\title{
BMJ Open CT-diagnosed emphysema and prognosis of chronic airflow obstruction: a retrospective study
}

\author{
Kazuyoshi Kurashima, ${ }^{1}$ Chiaki Fukuda, ${ }^{1}$ Keitaro Nakamoto, ${ }^{1}$ Yotaro Takaku, ${ }^{1}$ \\ Naoya Hijikata, ${ }^{1}$ Toshiko Hoshi, ${ }^{2}$ Tetsu Kanauchi, ${ }^{2}$ Miyuki Ueda, ${ }^{2}$ \\ Noboru Takayanagi, ${ }^{1}$ Yutaka Sugita, ${ }^{1}$ Ryuichiro Araki ${ }^{3}$
}

To cite: Kurashima $\mathrm{K}$, Fukuda C, Nakamoto K, et al. CT-diagnosed emphysema and prognosis of chronic airflow obstruction: a retrospective study. BMJ Open 2013;3:e003541. doi:10.1136/bmjopen-2013003541

- Prepublication history and additional material for this paper is available online. To view these files please visit the journal online (http://dx.doi.org/10.1136/ bmjopen-2013-003541)

Received 4 July 2013 Revised 9 September 2013 Accepted 24 September 2013

\section{(a) CrossMark}

${ }^{1}$ Department of Respiratory Medicine, Saitama Cardiovascular and Respiratory Center, Kumagaya, Saitama, Japan ${ }^{2}$ Department of Radiology, Saitama Cardiovascular and Respiratory Center, Kumagaya, Saitama, Japan ${ }^{3}$ Community Health Science Center, Saitama Medical University, Moroyama-machi, Saitama, Japan

\section{Correspondence to}

Dr Kazuyoshi Kurashima; kurashima.kazuyoshi@pref. saitama.lg.jp

\section{ABSTRACT}

Objective: CT-diagnosed emphysema is associated with poor prognosis in chronic obstructive pulmonary disease (COPD). Its clinical impacts on prognoses of asthma with chronic airflow obstruction (CAO) are not well known. We sought to compare mortalities and prognostic factors in COPD and asthma with CAO by the presence or absence of CT-diagnosed emphysema. Design: Retrospective cohort study.

Setting: Referral centre hospital for respiratory disease. Participants: 1272 patients aged over 40 years with CAO (January 2000 to December 2011). CAO was defined as a forced expiratory volume in $1 \mathrm{~s} / f$ orced vital capacity $<0.7$ after bronchodilator use throughout the observation period.

Primary and secondary outcome measurements: Overall mortality served as the primary endpoint. We compared mortalities and prognostic factors of COPD and asthma subgroups with or without emphysema. Secondary endpoints were the prevalence of COPD and asthma in patients with CAO.

Results: Overall, diagnoses included COPD with emphysema in $517(40.6 \%)$ patients, COPD without emphysema in 104 (8.2\%) patients, asthma with emphysema in 178 (13.9\%) patients, asthma without emphysema in 169 (13.3\%) patients, other respiratory diseases (RD) with emphysema in 128 (10.1\%) patients, and other RD without emphysema in $176(13.8 \%)$ patients. Patients with asthma without emphysema had the best prognosis followed by those with asthma with emphysema, COPD without emphysema and COPD with emphysema. Each subgroup had distinct prognostic factors. Presence of emphysema was an independent risk factor for de novo lung cancer among patients with $\mathrm{CAO}$.

Conclusions: Patients with asthma with CAO have a better prognosis than patients with COPD. The presence of CT-diagnosed emphysema predicts poor prognosis in COPD and asthma with CAO.

\section{INTRODUCTION}

Chronic obstructive pulmonary disease (COPD) is characterised by not fully reversible airflow obstruction in patients with risk

\section{Strengths and limitations of this study}

This will be the first study to compare prognosis of the subgroups of chronic obstructive pulmonary disease and asthma with chronic airflow obstruction (CAO) divided by the CT scan findings of emphysema.

- The prognosis of asthma with CAO was evaluated in the period after inhaled corticosteroids had become first-line therapy for asthma.

- This is a large-scale cohort study, but the data are derived from a single centre and the study is retrospective.

factors (tobacco, occupation and air pollution). ${ }^{1}$ It is also recognised that various respiratory diseases (RD) other than COPD such as asthma, bronchiectasis or old tuberculosis may have similar chronic airflow obstruction (CAO) as a postbronchodilator forced expiratory volume in $1 \mathrm{~s}$ (FEV1)/ forced vital capacity (FVC) persistently under $0.7 .^{2-4}$ Recently, it has been recognised that emphysematous change as assessed by highresolution CT (HRCT) scan is a more important prognostic factor than FEV1 in patients with COPD. ${ }^{5}$ However, the clinical significance of HRCT-diagnosed emphysema in the prognosis of other RD such as asthma with fixed airflow obstruction is not well known.

We hypothesised that HRCT-diagnosed emphysema is associated with the prognosis of the patients with $\mathrm{CAO}$ not limited to patients with COPD. We sought to compare the prognosis and prognostic factors of the phenotypes of COPD and asthma with CAO classified by the HRCT findings of emphysema. We also examined the prevalence of these phenotypes and other RD in consecutive patients with $\mathrm{CAO}$ to clarify the impact of differentiating these phenotypes. 


\section{METHODS}

\section{Patients}

We reviewed 1960 consecutive patients older than 40 years of age with initial postbronchodilator FEV1/ FVC $<0.7$ who presented to the Saitama Cardiovascular and Respiratory Center (a tertiary referral centre with 155 beds for RD) in Saitama, Japan, from 2000 through 2011. CAO was defined to be an FEV1/FVC ratio of $<0.7$ after bronchodilator use throughout the observation period. We excluded $326(16.6 \%)$ patients who did not undergo an HRCT examination or who did not receive a complete diagnosis, $133(6.8 \%)$ patients who had lung cancer at the entry examination, and 229 (11.7\%) patients whose postbronchodilator FEV1/FVC recovered to $>0.7$ during the observation period. Finally, we studied 1272 patients with $\mathrm{CAO}$ who underwent an HRCT examination.

\section{Study design}

This was a retrospective cohort study in which clinical data were collected from medical records. Survival status was obtained from medical records and/or telephone interviews.

All deaths were classified into the following five groups: (1) primary RD, (2) lung cancer, (3) malignancy other than lung cancer, (4) respiratory infectious diseases and (5) other or unknown. The HRCT study was ordered by the chest physician in charge for a closer examination of symptoms or evaluation of the diseases. The algorithm used to classify $\mathrm{CAO}$ is shown in online supplementary figure S1. All tests involved in the study were taken in a stable phase, with no evidence of any exacerbations for at least 6 weeks. HRCT images obtained within 6 months of the initiation time were considered acceptable for the evaluation. Medications used from the start of the observation period were also recorded.

The criteria used to classify patients with CAO included the following: (1) COPD with emphysema: presence of macroscopic emphysema on HRCT with a smoking history of at least 10 pack-years without other respiratory complications; (2) COPD without emphysema: no macroscopic emphysema on HRCT with a smoking history of at least 10 pack-years without other respiratory complications; (3) asthma with emphysema: presence of macroscopic emphysema on HRCT and fit the criteria for asthma ${ }^{6}$; asthma symptoms or history, a postbronchodilator increase in FEV1 of $>12 \%$ and $200 \mathrm{~mL}$, evidence of at least one of the following, sputum eosinophilia $(>3 \%)$ or increased exhaled nitric oxide ( $>30 \mathrm{ppb})$ or evidence of atopy; (4) asthma without emphysema: no macroscopic emphysema on HRCT and fit the above criteria for asthma; (5) other $\mathrm{RD}$ with emphysema: presence of macroscopic emphysema on HRCT and fulfil the criteria for other RD except asthma; and (6) other RD without emphysema: no macroscopic emphysema on HRCT and presence of other RD except asthma. Special care was taken to diagnose possible lung diseases by respiratory specialists and radiology specialists in our clinic for more than a decade, and all the necessary complementary tests were performed in this respect. Old pulmonary tuberculosis and pneumoconiosis were diagnosed by CT findings and history. Non-tuberculous mycobacterial lung diseases were diagnosed by the2007 American Thoracic Society (ATS)/Infectious Disease Society of America (IDSA) diagnostic criteria. ${ }^{7}$ Chronic hypersensitivity pneumonitis, ${ }^{8}$ diffuse panbronchiolitis, ${ }^{9}$ pulmonary Langerhans cell histiocytosis, ${ }^{10}$ sarcoidosis, ${ }^{11}$ bronchial diseases due to rheumatoid arthritis, ${ }^{12}$ bronchiolitis obliterans ${ }^{13}$ and other miscellaneous diseases were diagnosed as previously described.

\section{High-resolution CT}

HRCT scans were performed in full inspiration with a HiSpeed Advantage CT scanner (GE Medical Systems, Milwaukee, Wisconsin, USA) with a slice thickness of $1 \mathrm{~mm}$, scanning time of $1 \mathrm{~s}$, voltage of $140 \mathrm{kV}$, tube current of $200 \mathrm{~mA}$ and field of view of $20 \mathrm{~cm}$. The presence of emphysema was defined as well-demarcated areas of decreased attenuation in comparison with a contiguous normal lung and marginated by a very thin or no wall with upper zone predominance. The presence of emphysema and CT diagnosis were determined
Figure 1 Phenotypes of chronic airflow obstruction (CAO). CAO was defined as postbronchodilator FEV1/ FVC $<0.7$ throughout the observation period. Patients were classified by the high-resolution CT findings of emphysema and other clinical examinations. FEV1, forced expiratory volume in $1 \mathrm{~s} ;$ FVC, forced vital capacity; $\mathrm{RD}$, respiratory diseases.
1960 subjects with FEV1/FVC ratio $<0.7$ after bronchodilator were recruited

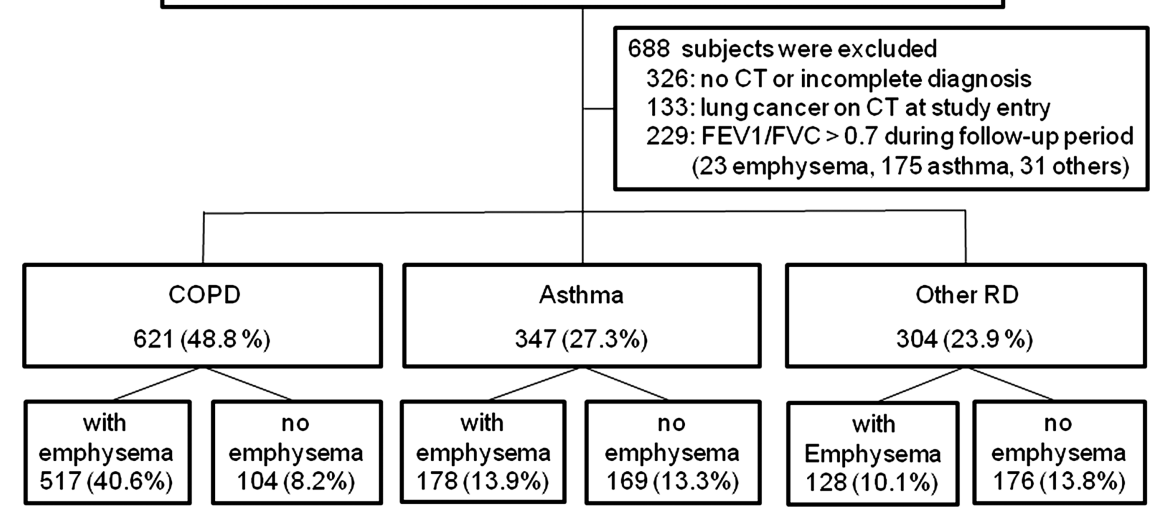


by two radiologists with extensive experience in the diagnosis of RD; all were blind to other researchers. The CT findings of usual interstitial pneumonia or other interstitial pneumonia were diagnosed based on the 2002 ATS/ European Respiratory Society (ERS) classification. ${ }^{14}$ The presence of bronchiectasis was based on criteria by Naidich et $a l^{15}$ Mild dilation of the airways in COPD was not considered as bronchiectasis.

\section{Pulmonary function tests}

Pulmonary function tests were performed with a CHESTAC-8800 spirometer (Chest MI Corp, Tokyo, Japan). Predicted values of spirometric measurements were derived from the guidelines for pulmonary function tests issued by the ATS. ${ }^{16}$ Spirometry was performed before and $30 \mathrm{~min}$ after inhalation of $200 \mu \mathrm{g}$ of salbutamol, and the data obtained after inhalation of salbutamol were used for evaluation.

\section{Statistical analysis}

Categorical baseline characteristics are summarised by per cent, and continuous characteristics are reported as mean \pm SD. Comparisons between subgroups for descriptive summaries were performed by analysis of variance. We compared the baseline characteristics to investigate potential risk factors of mortality. We chose the variables for entry into univariate Cox regression analysis from the results that showed significant effectors with previously recognised clinical significance: clinical phenotype, sex, age, body mass index (BMI), smoking history (1 cigarettexyear), current smoking, FVC, FEV1, FEV1/ FVC, FEV1 reversibility to bronchodilators, annual change in FEV1 and medications used from the start of observation. We then performed multivariate Cox regression analysis with backward variable selection.

Survival in each patient subgroup was estimated by the Kaplan-Meier analysis. Mortality rates from any cause for two clinical phenotypes were compared with a log-rank test. Time was defined from initial examination until 1 March 2012 or until death or loss to follow-up before 1 March 2012.

Differences in causes of mortality were analysed by the Fisher-Freeman-Halton test, and risk for de novo lung cancer was analysed by multiple logistic regression analysis with Firth's bias reduction. A $\mathrm{p}$ value of $<0.05$ was considered statistically significant. All data were analysed with SAS V.9.1.3 SP4 (SAS Institute Inc, Cary, North Carolina, USA).

\section{RESULTS}

Prevalence of COPD, asthma and other RD in patients with CAO

Of the 1272 patients with postbronchodilator FEV1/ FVC $<0.7$ throughout the observation period, 517 (40.6\%) had COPD with emphysema, 104 (8.2\%) had COPD without emphysema, 178 (14\%) had asthma with emphysema, $169(13.3 \%)$ had asthma without emphysema, 128 (10\%) had other RD with emphysema and $176(13.8 \%)$ had other RD without emphysema (figure 1). Other RD with or without emphysema are shown in online supplementary table S1.

\section{Patient characteristics}

The patient characteristics of each group are shown in table 1 . In total, $176(13.8 \%)$ patients were women, and $1131(88.9 \%)$ patients had a smoking history. All of the patients with COPD and all of the patients with emphysema had smoking histories. Patients with COPD with emphysema had the lowest BMI. The mean \%FEV1 was lowest in patients with asthma with emphysema. The annual decline of FEV1 was largest in the patients with asthma with emphysema subgroup and smallest in the patients with COPD without emphysema subgroup.

\section{Mortalities of CAO phenotypes}

The survival curves and rates for the patient subgroups are shown in figure 2 and online supplementary table 2, and the prognostic factors of overall patients are summarised in online supplementary table S3. Although other RD with or without emphysema are a mixture of miscellaneous diseases, their survival curves were also presented in figure 2 for reference. Patients with asthma had better overall survival than patients with COPD when adjusted for other potential variables (see online supplementary table S3).

Patients with asthma and no emphysema had the best prognosis followed by those with asthma with emphysema, COPD without emphysema and COPD with emphysema. Overall survivals between patients with COPD with or without emphysema, and overall survivals between patients with asthma or without emphysema were significantly different by log-rank test $(\mathrm{p}=0.004$ and $\mathrm{p}=0.016$, respectively). Even when adjusted for potential variables, the presence of emphysema was a significant predictor of death in COPD but not in asthma (see online supplementary table S4).

Mortality risks from any cause for each clinical subtype except for other RD are shown in table 2. Age, BMI and $\%$ FVC were independent prognostic factors in COPD with emphysema, whereas age and $\% \mathrm{FVC}$ were the independent prognostic factors for COPD without emphysema. In the asthma with emphysema subgroup, low $\%$ FEV1 and presence of wheezing were negative prognostic factors. In the asthma without emphysema subgroup, age and use of inhaled corticosteroids (ICSs) were significant prognostic factors.

\section{Causes of mortality and de novo lung cancer}

There were significant differences in the causes of mortality among the subgroups (Fisher's statistic was 23.59, and the double-sided $\mathrm{p}$ value was 0.020 , table 3 ). In the COPD with emphysema subgroup, about one-third of the causes of death were de novo malignant diseases and about one-fourth of the cause of death was lung cancer. During the observation period, de novo lung 
Table 1 Characteristics of the patients with chronic airflow obstruction

\begin{tabular}{|c|c|c|c|c|c|c|c|}
\hline \multirow[b]{2}{*}{ Emphysema } & \multicolumn{2}{|l|}{ COPD } & \multicolumn{2}{|l|}{ Asthma } & \multicolumn{2}{|l|}{ Other RD } & \multirow[b]{2}{*}{ p Value } \\
\hline & Yes & No & Yes & No & Yes & No & \\
\hline Number & $517,40.6 \%$ & $104,8.2 \%$ & $178,13.9 \%$ & $169,13.3 \%$ & $128,10.1 \%$ & $176,13.8 \%$ & \\
\hline Age & $69.1 \pm 8.3$ & $70.4 \pm 7.2$ & $67.6 \pm 7.9$ & $64.5 \pm 9.5$ & $70.6 \pm 7.9$ & $65.0 \pm 11.8$ & $<0.001$ \\
\hline Female sex $(n, \%)$ & $20,3.9$ & $10,9.6$ & $21,11.8$ & $55,32.7$ & $4,3.1$ & $66,37.5$ & $<0.001$ \\
\hline Body mass index & $21.2 \pm 3.6$ & $23.2 \pm 2.6$ & $21.9 \pm 3.3$ & $23.0 \pm 3.2$ & $22.2 \pm 3.6$ & $22.3 \pm 3.3$ & $<0.001$ \\
\hline Never smoker (n, \%) & 0 & 0 & 0 & $62,36.9$ & 0 & $79,44.9$ & $<0.001$ \\
\hline Smoking index (pack-year) & $67.2 \pm 34.7$ & $57.6 \pm 28.3$ & $59.3 \pm 29.0$ & $22.9 \pm 24.5$ & $65.8 \pm 34.1$ & $20.5 \pm 25.4$ & $<0.001$ \\
\hline$\% F V C$ & $85.5 \pm 19.4$ & $86.4 \pm 18.9$ & $86.0 \pm 19.2$ & $86.1 \pm 18.4$ & $84.6 \pm 22.1$ & $76.4 \pm 18.5$ & $<0.001$ \\
\hline$\% F E V 1$ & $59.6 \pm 24.4$ & $71.2 \pm 21.9$ & $56.0 \pm 21.8$ & $66.5 \pm 22.1$ & $70.6 \pm 28.5$ & $65.7 \pm 21.3$ & $<0.001$ \\
\hline FEV1/FVC & $44.7 \pm 12.7$ & $53.3 \pm 9.9$ & $44.4 \pm 11.9$ & $52.7 \pm 11.1$ & $53.2 \pm 12.8$ & $56.0 \pm 11.8$ & $<0.001$ \\
\hline Reversibility, per cent & $8.1 \pm 8.1$ & $7.7 \pm 7.6$ & $17.7 \pm 13.0$ & $17.1 \pm 12.3$ & $6.8 \pm 7.4$ & $9.5 \pm 10.6$ & $<0.001$ \\
\hline Reversibility, $\mathrm{mL}$ & $95.2 \pm 85.8$ & $108.4 \pm 96.5$ & $194.4 \pm 139.4$ & $218.0 \pm 158.8$ & $96.2 \pm 92.9$ & $117.4 \pm 120.8$ & $<0.001$ \\
\hline $\begin{array}{l}\delta \text { FEV1 (mL/year) } \\
\text { Medication (n, \%) }\end{array}$ & $-34.4 \pm 69.8$ & $-12.9 \pm 69.2$ & $-50.2 \pm 59.0$ & $-12.1 \pm 114.5$ & $-42.8 \pm 73.3$ & $-31.1 \pm 93.4$ & 0.002 \\
\hline Long-acting $\beta$ 2-receptor agonist & $164,31.7 \%$ & $31,29.8 \%$ & $93,52.2 \%$ & $122,72 \%$ & $7,5.5 \%$ & $12,6.8 \%$ & $<0.001$ \\
\hline Long-acting muscarinic receptor antagonist & $181,35.0 \%$ & $29,27.9 \%$ & $48,27.0 \%$ & $4,2.4 \%$ & $17,13.3 \%$ & $4,2.3 \%$ & $<0.001$ \\
\hline Inhaled corticosteroids & $142,27.5 \%$ & $42,40.4 \%$ & $129,72.5 \%$ & $152,89.9 \%$ & $16,12.5 \%$ & $27,15.3 \%$ & $<0.001$ \\
\hline Methylxanthine & $60,11.6 \%$ & $13,12.5 \%$ & $37,20.8 \%$ & $22,13.1 \%$ & $22,17.2 \%$ & $12,6.8 \%$ & $<0.001$ \\
\hline Observation period (year) & $4.3 \pm 2.9$ & $4.6 \pm 3.2$ & $5.8 \pm 3.2$ & $5.9 \pm 3.0$ & $4.1 \pm 2.8$ & $4.2 \pm 2.8$ & $<0.001$ \\
\hline
\end{tabular}

COPD, chronic obstructive pulmonary disease; FEV1, forced expiratory volume in $1 \mathrm{~s}$; FVC, forced vital capacity; RD, respiratory diseases. 


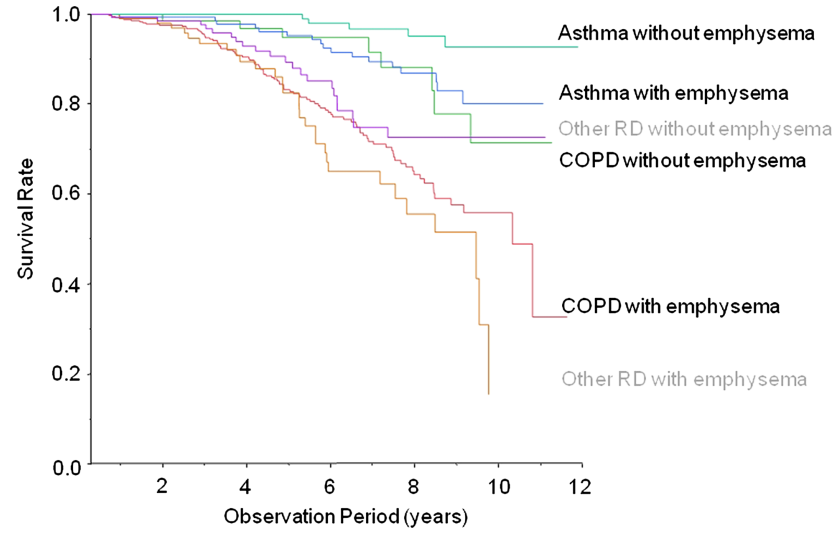

Figure 2 Kaplan-Meier survival curves for phenotypes of chronic airflow obstruction. Prognoses between patients with COPD with or without emphysema, and prognoses between patients with asthma with or without emphysema were significantly different by log-rank test $(p=0.004$ and $p=0.016$, respectively). COPD, chronic obstructive pulmonary disease $\mathrm{RD}$, respiratory diseases.

cancers were observed in 38/517 $(7.7 \%)$ in COPD with emphysema, 5/104 (4.8\%) in COPD without emphysema, $4 / 178(2.2 \%)$ in asthma with emphysema, 2/168 $(1.1 \%)$ in asthma without emphysema, 8/128 (6.25\%) in other RD with emphysema and $3 / 176(1.7 \%)$ in other RD without emphysema. Therefore, we analysed the risk of de novo lung cancer for the 1272 patients with CAO (table 4). The presence of emphysema was a significant predictor for de novo lung cancer (HR 2.055, 95\% CI 1.042 to 4.053; $\mathrm{p}=0.038$ ), and asthma was a negative predictor for de novo lung cancer (HR 0.349, 95\% CI 0.143 to $0.849 ; \mathrm{p}=0.020)$.

\section{DISCUSSION}

Patients with CAO, postbronchodilator FEV1/FVC always below 0.7, are often diagnosed just as COPD and treated similarly. In this study, we classified the patients with $\mathrm{CAO}$ into $\mathrm{COPD} /$ asthma/other $\mathrm{RD}$, and then subdivided them by the CT scan findings of emphysema. We showed that COPD comprised only about half of the patients with $\mathrm{CAO}$, and each subgroup had distinct prognosis and prognostic factors. Prognosis of the patients with asthma was better than that of COPD in patients with $\mathrm{CAO}$, and the presence of emphysema was associated with poor prognosis in COPD and asthma. In addition, the presence of emphysema and the presence of asthma were positive and negative risk factors for de novo lung cancer, respectively, in patients with CAO. These data clearly show the impact of differential diagnosis of COPD and usefulness of CT-diagnosed emphysema for the management of patients with CAO.

This study was a retrospective but large-scale singlecentre study. In 2000, we introduced a diagnostic algorithm for the patients who showed postbronchodilator FEV1<0.7. ${ }^{17}$ HRCT was used to diagnose the presence of emphysema, possible lung cancer, interstitial changes in any lung field, bronchiectasis and miscellaneous diseases of specific clinical entities. Although the present study is retrospective, there is an advantage for diagnosis by having long-term clinical records including responses to ICS treatments. This would be important for diagnosing asthma with similar lung functions to COPD because the presence of intermittent wheezing, variability in the peak flow rate or responses to ICSs might be identified in a follow-up period after initial diagnosis. Sputum eosinophilia and an elevated level of exhaled nitric oxide are well-established markers to distinguish asthma from COPD once fixed airflow obstruction has developed. ${ }^{18} 19$ We examined these markers to diagnose allergic asthma.

COPD has been thought to be an overlap between chronic bronchitis, emphysema and asthma, and this concept was represented in a Venn diagram and recognised by the ATS. ${ }^{20} 21$

We observed that a part of the patients with COPD had no emphysema as best diagnosed by HRCT and careful differential diagnoses. It is not clear whether they have microscopic emphysema, but they had distinct prognosis and prognostic factors from that of COPD with emphysema. The coexistence of asthma and COPD is known as the overlap syndrome. ${ }^{22} 23$ The overlap syndrome of asthma and COPD has been defined by the coexistence of increased variability of airflow in a patient with incompletely reversible airway obstruction. ${ }^{23}$ By this definition, all patients with asthma recruited in this study are considered to be a part of the overlap syndrome. In this study, we further classified asthma with $\mathrm{CAO}$ by the presence of emphysema. We found that the presence of emphysema predicted poor overall survival in patients with asthma with CAO. Although HR was not significant when adjusted by other potential variables, these subgroups had distinct prognostic factors. In patients with asthma and emphysema, their survival was predicted by the severity of airflow obstruction at a stable period, whereas in patients with asthma without emphysema, the use of ICSs was a critical factor for prognosis regardless of airflow obstruction in a stable state.

Recently, emphysema with the usual interstitial pneumonia or other interstitial pneumonia has attracted as much attention as combined pulmonary fibrosis with emphysema. ${ }^{24}$ Other RD with or without emphysema comprised $23 \%$ of the patients with CAO. HRCT is also useful to detect respiratory comorbidities and other RD. For example, HRCT is sensitive to diagnose interstitial shadows or small airway disease in patients with rheumatoid arthritis. ${ }^{25}$ However, because these groups are a mixture of miscellaneous diseases, they are not considered as one group. Therefore, we only showed their survival curves just for reference purposes.

One of the main findings of this study is that patients with asthma with CAO had a significantly better prognosis than those with COPD. It is well accepted that disease in patients with asthma who develop incompletely 
Table 2 Univariate and multivariate analysis of the risk of mortality in subgroups

\begin{tabular}{|c|c|c|c|c|c|c|}
\hline \multirow{2}{*}{$\begin{array}{l}\text { Subgroup } \\
\text { Variable }\end{array}$} & \multicolumn{3}{|c|}{ Univariate Cox regression } & \multicolumn{3}{|c|}{ Multivariate Cox regression final model } \\
\hline & Crude HR & $95 \% \mathrm{Cl}$ & p Value & Adjusted HR & $95 \% \mathrm{Cl}$ & p Value \\
\hline \multicolumn{7}{|l|}{ COPD with emphysema } \\
\hline Age, per 1 year increase & 1.056 & 1.024 to 1.089 & $<0.001$ & 1.038 & 1.003 to 1.074 & 0.033 \\
\hline BMI, per 1 unit increase & 0.853 & 0.792 to 0.917 & $<0.001$ & 0.904 & 0.835 to 0.978 & 0.012 \\
\hline$\% F V C$, per $1 \%$ increase & 0.967 & 0.956 to 0.978 & $<0.001$ & 0.965 & 0.947 to 0.983 & $<0.001$ \\
\hline$\% F E V 1$, per $1 \%$ increase & 0.978 & 0.968 to 0.988 & $<0.001$ & & & \\
\hline FEV1 reversibility, per $1 \mathrm{~mL}$ increase & 0.995 & 0.992 to 0.998 & 0.002 & & & \\
\hline None & Reference & - & - & & & \\
\hline Positive & 0.628 & 0.398 to 0.992 & 0.046 & & & \\
\hline \multicolumn{7}{|l|}{ Use of LAMA } \\
\hline None & Reference & - & - & & & \\
\hline Positive & 0.547 & 0.353 to 0.849 & 0.007 & & & \\
\hline \multicolumn{7}{|l|}{ COPD w/o emphysema } \\
\hline Age, per 1 year increase & 1.152 & 1.003 to 1.323 & 0.045 & 1.236 & 1.031 to 1.482 & 0.022 \\
\hline$\% F V C$, per $1 \%$ increase & 0.952 & 0.920 to 0.985 & 0.004 & 0.918 & 0.854 to 0.985 & 0.018 \\
\hline$\% F E V 1$, per $1 \%$ increase & 0.964 & 0.854 to 0.997 & 0.030 & & & \\
\hline \multicolumn{7}{|l|}{ Asthma with emphysema } \\
\hline \multicolumn{7}{|l|}{ Wheezing } \\
\hline None & Reference & - & - & Reference & - & - \\
\hline Positive & 1.431 & 1.129 to 1.812 & 0.003 & 1.654 & 1.236 to 2.213 & 0.001 \\
\hline Age, per 1 year increase & 1.079 & 1.003 to 1.161 & 0.041 & & & \\
\hline FEV1 reversibility, per $1 \mathrm{~mL}$ increase & 0.994 & 0.990 to 0.999 & 0.015 & & & \\
\hline \multicolumn{7}{|l|}{ Asthma w/o emphysema } \\
\hline Age, per 1 year increase & 1.174 & 1.047 to 1.316 & 0.006 & 1.186 & 1.008 to 1.394 & 0.039 \\
\hline \multicolumn{7}{|l|}{ Use of ICSs } \\
\hline None & Reference & - & - & Reference & - & - \\
\hline Positive & 0.091 & 0.015 to 0.540 & 0.008 & 0.091 & 0.014 to 0.594 & 0.012 \\
\hline$\%$ FVC, per $1 \%$ increase & 0.938 & 0.883 to 0.997 & 0.038 & & & \\
\hline
\end{tabular}

reversible airflow obstruction resembles COPD in terms of age, airway complications and the pattern of airway inflammation with increased presence of airway neutrophils. ${ }^{26-29}$ The data of this study seem rather surprising because asthma patients with emphysema had the lowest baseline FEV1 and largest annual decline of

Table 3 Mortality causes in the study groups

\begin{tabular}{|c|c|c|c|c|c|c|c|}
\hline & $\begin{array}{l}\text { COPD with } \\
\text { emphysema }\end{array}$ & $\begin{array}{l}\text { COPD without } \\
\text { emphysema }\end{array}$ & $\begin{array}{l}\text { Asthma with } \\
\text { emphysema }\end{array}$ & $\begin{array}{l}\text { Asthma } \\
\text { without } \\
\text { emphysema }\end{array}$ & $\begin{array}{l}\text { Other RD with } \\
\text { emphysema }\end{array}$ & $\begin{array}{l}\text { Other RD } \\
\text { without } \\
\text { emphysema }\end{array}$ & p Value \\
\hline $\begin{array}{l}\text { Primary } \\
\text { respiratory } \\
\text { causes }\end{array}$ & 34 (35.7\%) & $5(62.5 \%)$ & $6(37.5 \%)$ & $2(40 \%)$ & 15 (51.7\%) & 7 (33.3\%) & 0.020 \\
\hline Lung cancer & $22(23.1 \%)$ & 0 & $1(6.3 \%)$ & 0 & 3 (10.3\%) & $2(9.5 \%)$ & \\
\hline $\begin{array}{l}\text { Other } \\
\text { malignant } \\
\text { diseases }\end{array}$ & $10(10.5 \%)$ & 0 & $1(6.3 \%)$ & 0 & $1(3.4 \%)$ & 0 & \\
\hline $\begin{array}{l}\text { Respiratory } \\
\text { infectious } \\
\text { diseases }\end{array}$ & $6(6.3 \%)$ & $1(12.5 \%)$ & $3(18.7 \%)$ & 0 & $2(6.9 \%)$ & 7 (33.3\%) & \\
\hline $\begin{array}{l}\text { Other causes/ } \\
\text { unknown }\end{array}$ & $23(24.2 \%)$ & $2(25.0 \%)$ & 5 (31.2\%) & $3(60 \%)$ & $8(27.6 \%)$ & $5(23.8 \%)$ & \\
\hline Total number & 95 & 8 & 16 & 5 & 29 & 21 & \\
\hline
\end{tabular}




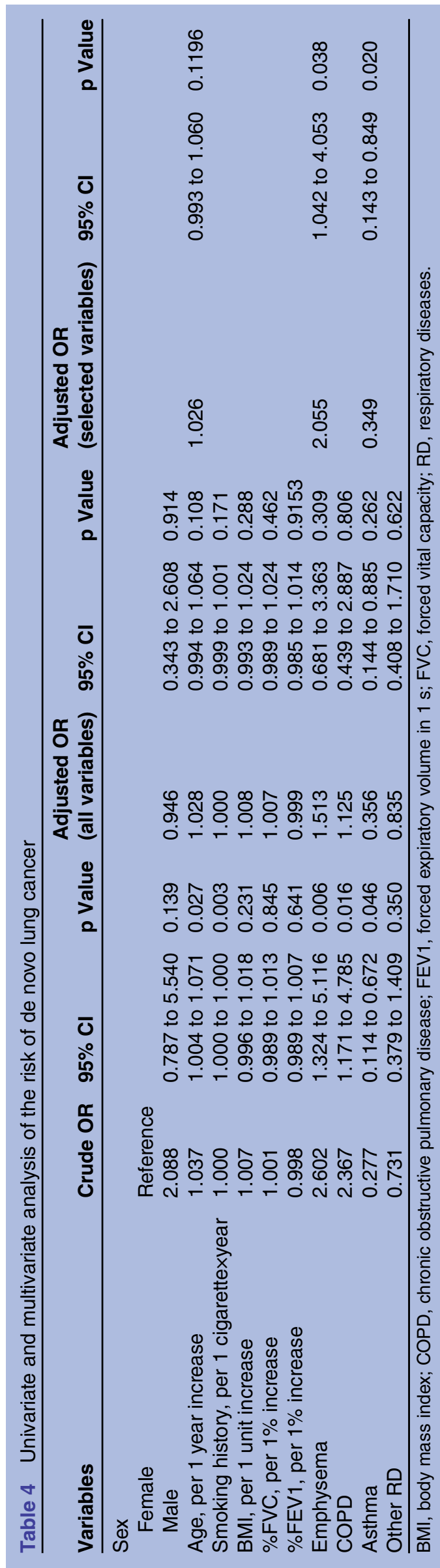

FEV1 among patients with CAO. A previous report showed that the prognosis of patients with COPD with airway hyper-responsiveness was worse than that of patients with COPD without airway hyperresponsiveness. ${ }^{30}$ In that study, which was published in 2000 , the patients were recruited from the 1960s to the 1970 s, a period before ICSs had become first-line therapy for asthma. In addition, death by lung cancer was accumulated in COPD. It could partially explain the poorer prognosis of COPD compared to asthma with CAO.

In a previous prospective study, published in 2010, the extent of emphysema was associated with COPD prognosis. ${ }^{5}$ Another study showed that emphysema severity is independently associated with a rapid annual decline in FEV1 in patients with COPD. ${ }^{31}$ Although the definition of emphysema subgroups is different from that of previous studies, ${ }^{51}$ the results of this study are in accordance with these reports in that the survival rate and annual decline in COPD without emphysema were better than those in COPD with emphysema $(p=0.004$ by log-rank test, and $\mathrm{p}=0.008$ by Mann-Whitney test, respectively). Low body weight was a poor prognostic factor in patients with COPD with emphysema, but not in patients with COPD without emphysema.

Lung cancer is an important cause of mortality in COPD, and in a recent large cohort study, older age, low BMI, early global initiative for chronic obstructive lung disease stage and low diffusion capacity for carbon monoxide (DLco) were independent risk factors for de novo lung cancer in COPD. ${ }^{32}$ Among the patients with CAO, we showed that emphysema was a positive risk factor for lung cancer $(\mathrm{HR}=2.06)$ and asthma was a negative risk factor $(\mathrm{HR}=0.35)$. The result of asthma should be interrelated with caution because it might reflect increased risk for lung cancer in patients without asthma (COPD plus other RD). In fact, recent meta-analysis showed that the relative risk for lung cancer associated with asthma was $1.28 .^{33}$ However, knowledge of the relative risks for lung cancer may be helpful for the follow-up of patients with CAO.

There are several limitations that should be noted. This study was retrospective, and therefore some clinical and laboratory findings were not available. We could measure residual volume (RV), total lung capacity (TLC) and low DLco in only a portion of the patients at the start of observation; therefore, we excluded these parameters from the analysis of prognosis. In this study, $\% \mathrm{FVC}$ was a stronger prognostic factor than \%FEV1 in patients with COPD, although they were very similar in univariate analysis. \% FVC was most closely correlated with $\mathrm{RV} / \mathrm{TLC}(\mathrm{r}=-0.730, \mathrm{p}<0.001)$ among pulmonary function parameters, so reduced \%FVC might reflect increased RV/TLC in COPD. In this study, bronchiectasis was diagnosed in a very strict sense. ${ }^{15}$ Mild dilation of the bronchi in COPD was not considered. Our data are in discordance with a previous report demonstrating the high prevalence of bronchiectasis in COPD. ${ }^{34}$ If we 
found real bronchiectasis, we made strong efforts to find a more specific diagnosis such as old tuberculosis, nontuberculous mycobacterial lung diseases, diffuse panbronchiolitis, bronchial diseases due to rheumatoid arthritis, bronchiolitis obliterans and so on.

In conclusion, patients with not fully reversible airflow obstruction are heterogeneous. Prognosis of the patients with asthma with $\mathrm{CAO}$ was better than that of those with COPD in spite of the similar age and lung functions. The presence of emphysema is associated with poor prognosis in COPD and in asthma with CAO. Recognition of HRCT findings of emphysema and allergic asthma in patients with $\mathrm{CAO}$ would be important because clinicians could have different strategies for these conditions. The data of this study suggest that the use of ICSs and control of airway obstruction are critically important for the prognosis of asthma with CAO. In patients with COPD with emphysema, preserved body weight and lung functions were important for prognosis, but de novo lung cancer should be considered regardless of age and degree of airflow obstruction.

Acknowledgements The authors would like to thank Chie Ohta, Daido Tokunaga, Yousuke Miyahara, Nao Kagiyama, Takashi Ishiguro and Tsutomu Yanagisawa for providing treatment and care for study patients.

Contributors KK designed the study and wrote the manuscript. CF, KN, YT, $\mathrm{NH}$, NT and YS acquired the clinical data. TH, TK and MU analysed the CT findings. RA analysed the data.

Funding This research received no specific grant from any funding agency in the public, commercial or not-for-profit sectors.

Competing interests None.

Ethics approval The study was approved by the Institutional Review Board of Saitama Cardiovascular and Respiratory Center (IRB No. 2012001).

Provenance and peer review Not commissioned; externally peer reviewed.

Data sharing statement Distribution and statistical difference graphs of annual decline of forced expiratory volume in $1 \mathrm{~s}$ (FEV1), FEV1 reversibility, relationships of FEV1 or forced vital capacity to low diffusion capacity for carbon monoxide, and residual volume are available by email to the corresponding author.

Open Access This is an Open Access article distributed in accordance with the Creative Commons Attribution Non Commercial (CC BY-NC 3.0) license, which permits others to distribute, remix, adapt, build upon this work noncommercially, and license their derivative works on different terms, provided the original work is properly cited and the use is non-commercial. See: http:// creativecommons.org/licenses/by-nc/3.0/

\section{REFERENCES}

1. From the Global Strategy for the Diagnosis, Management and Prevention of COPD, Global Initiative for Chronic Obstructive Lung Disease (GOLD), 2011. http://www.goldcopd.org/ (accessed 12 Dec 2012)

2. Anonymous. Terminology, definitions, and classification of chronic pulmonary emphysema and related conditions. A report of the conclusions of the Ciba guest symposium. Thorax 1959;14:286-99.

3. Rabe KF, Hurd S, Anzueto A, et al. Global initiative for chronic obstructive lung disease. Global strategy for the diagnosis, management and prevention of chronic obstructive pulmonary disease: GOLD executive summary. Am J Respir Crit Care Med 2007; $176: 532-55$

4. Shirtcliffe $\mathrm{P}$, Weatherall $\mathrm{M}$, Travers J, et al. The multiple dimensions of airways disease: targeting treatment to clinical phenotypes. Curr Opin Pulm Med 2011;17:72-8.
5. Haruna A, Muro S, Nakano Y, et al. CT scan findings of emphysema predict mortality in COPD. Chest 2010;138:635-40.

6. From the Global Initiative for Asthma Management and Prevention. 2011. http://www.ginasthma.org/ (accessed 20 June 2012).

7. Griffith DE, Aksamit T, Brown-Elliott BA, et al. ATS mycobacterial disease subcommittee. American Thoracic Society; Infectious Disease Society of America. An official ATS/IDSA statement: diagnosis, treatment, and prevention of nontuberculous mycobacterial disease. Am J Respir Crit Care Med 2007;175:367-416.

8. Richerson HB, Bernstein IL, Fink JN, et al. Guidelines for the clinical evaluation of hypersensitivity pneumonitis. Report of the Subcommittee on Hypersensitivity Pneumonitis. J Allergy Clin Immunol 1989;84:839-44.

9. Nakata K. Revision of clinical guidelines for diffuse panbronchiolitis. In: Annual report on the study of diffuse lung disease in 1998. Grant in aid from the ministry of health and welfare of Japan. Tokyo, 1999:109-11.

10. Vassallo R, Ryu JH, Schroeder DR, et al. Clinical outcomes of pulmonary Langerhans'-cell histiocytosis in adults. $N$ Engl $\mathrm{J}$ Med 2002;346:484-90.

11. Hunninghake GW, Costabel U, Ando M, et al. ATS/ERS/WASOG statement on sarcoidosis. American Thoracic Society/European Respiratory Society/World Association of Sarcoidosis and other Granulomatous Disorders. Sarcoidosis Vasc Diffuse Lung Dis 1999;16:149-73.

12. Tsuchiya $\mathrm{Y}$, Takayanagi $\mathrm{N}$, Sugiura $\mathrm{H}$, et al. Lung diseases directly associated with rheumatoid arthritis and their relationship to outcome. Eur Respir J 2011;37:1411-17.

13. Devakonda A, Raoof S, Sung A, et al. Bronchiolar disorders: a clinical-radiological diagnostic algorithm. Chest 2010;137:938-51.

14. American Thoracic Society (ATS) and the European Respiratory Society (ERS). American Thoracic Society/the European Respiratory Society international multidisciplinary consensus classification of the idiopathic interstitial pneumonias. Am J Respir Crit Care Med 2002;165:277-304.

15. Naidich DP, McCauley DI, Khouri NF, et al. Computed tomography of bronchiectasis. J Comput Assist Tomogr 1982;6:437-44.

16. American Thoracic Society (ATS). Standardization of Spirometry, 1994 Update. Am J Respir Crit Care Med 1995;152:1107-36.

17. Kurashima K, Takayanagi N, Sato N, et al. High resolution CT and bronchial reversibility test for diagnosing COPD. Respirology 2005;10:316-22.

18. Brightling $\mathrm{CE}$, Ward $\mathrm{R}$, Goh $\mathrm{KL}$, et al. Eosinophilic bronchitis is an important cause of chronic cough. Am J Respir Crit Care Med 1999;160:406-10.

19. Gibson PG, Henry RL, Thomas P. Noninvasive assessment of airway inflammation in children: induced sputum, exhaled nitric oxide, and breath condensate. Eur Respir J 2000;16:1008-15.

20. Snider G. Chronic obstructive pulmonary disease: a definition and implication of structural determinants of airflow obstruction for epidemiology. Am Rev Respir Dis 1989;140:S3-8.

21. Standards for the diagnosis and care of patients with chronic obstructive pulmonary disease. American Thoracic Society. Am J Respir Crit Care Med 1995;152:S77-121.

22. Marsh SE, Travers J, Weatherall M, et al. Proportional classifications of COPD phenotypes. Thorax 2008;63:761-7.

23. Gibson PG, Simpson JL. The overlap syndrome of asthma and COPD: what are its features and how important is it? Thorax 2009;64:728-35.

24. Cottin V, Nunes H, Brillet PY, et al. Combined pulmonary fibrosis and emphysema: a distinct underrecognised entity. Eur Respir $J$ 2005;26:586-93.

25. Perez T, Remy-Jardin M, Cortet B. Airways involvement in rheumatoid arthritis: clinical, functional, and HRCT findings. Am J Respir Crit Care Med 1998;157:1658-65.

26. Bumbacea D, Campbell D, Nguyen L, et al. Parameters associated with persistent airflow obstruction in chronic severe asthma. Eur Respir J 2004;24:122-8.

27. Chalmers GW, MacLeod KJ, Thomson L, et al. Smoking and airway inflammation in patients with mild asthma. Chest 2001;120:1917-22.

28. Boulet LP, Lemière $\mathrm{C}$, Archambault $\mathrm{F}$, et al. Smoking and asthma: clinical and radiologic features, lung function, and airway inflammation. Chest 2006;129:661-8.

29. Panizza JA, James AL, Ryan G, et al. Mortality and airflow obstruction in asthma: a 17-year follow-up study. Intern Med J 2006;36:773-80.

30. Hospers JJ, Postma DS, Rijcken B, et al. Histamine airway hyper-responsiveness and mortality from chronic obstructive pulmonary disease: a cohort study. Lancet 2000;356:1313-17. 
31. Nishimura M, Makita $\mathrm{H}$, Nagai $\mathrm{K}$, et al. Annual change in pulmonary function and clinical phenotype in chronic obstructive pulmonary disease. Am J Respir Crit Care Med 2012;185:44-52.

32. de Torres JP, Marin JM, Casanova C, et al. Lung cancer in patients with chronic obstructive pulmonary disease-incidence and predicting factors. Am J Respir Crit Care Med 2011;184:913-19.
33. Rosenberger A, Bickeboller $\mathrm{H}$, McCormack V, et al. Asthma and lung cancer: a systemic investigation by the international lung cancer consortium. Carcinogenesis 2012;33:587-97.

34. Martinez-Garia MA, Soler-Cataluna JJ, Sanz YD, et al. Factors associated with bronchiectasis in patients with COPD. Chest $2011 ; 140: 1130-7$. 